\title{
COMPARATIVO DA EVOLUÇÃO DAS MANIFESTAÇÕES PATOLÓGICAS DE UMA EDIFICAÇẪO EM UM INTERVALO DE 5 ANOS
}

\author{
LIMA, NATHÁLIA \\ Graduada em Engenharia Civil \\ Universidade Católica de Pernambuco \\ PE; Brasil \\ nataliamvlima@gmail.com
}

\author{
NASCIMENTO, FERNANDO \\ Graduando em Engenharia Civil \\ Universidade Católica de Pernambuco \\ PE; Brasil \\ carlosfernando.gn@gmail.com
}

\author{
SANTOS, MANUELI \\ Mestranda em Engenharia Civil \\ Universidade Federal de Santa Catarina \\ $\mathrm{SC}$; Brasil \\ manuelisueni@hotmail.com
}

\author{
REIS, JOÃO \\ Mestrando em Engenharia Civil \\ Universidade Católica de Pernambuco \\ PE; Brasil \\ gabriel_julho10@hotmail.com \\ VALE, LEONARDO \\ Mestrando em Engenharia Civil \\ Universidade Católica de Pernambuco \\ PE; Brasil \\ leodovalle@outlook.com \\ MONTEIRO, ELIANA \\ Prof $^{a}$. Dr ${ }^{\mathrm{a}}$. em Engenharia Civil \\ Univ. Cat. de Pernambuco e Univ. de Pernambuco \\ PE; Brasil \\ eliana@poli.br
}

\section{RESUMO}

As estruturas de concreto armado começam a apresentar manifestações patológicas quando chegam perto do seu tempo de vida útil ou quando surge algum problema durante esse período. O presente artigo tem como finalidade o estudo de caso de uma edificação construída em 1967, localizada no campus da Universidade Federal de Pernambuco, que possui um laudo com um levantamento das manifestações patológicas executado em 2012 e no mesmo ano a edificação recebeu uma intervenção corretiva que realizado por uma empresa, mas não constava projeto de recuperação estrutural. Os problemas continuaram e em 2017 foi feito um novo laudo, que mostrou o aumento do número de estruturas que apresentam manifestações patológicas. Com a conclusão do trabalho foram descobertos novos problemas construtivos e foi possível fazer uma evolução desses problemas em 5 anos com acréscimo de quase 300\% no quantitativo de manifestações e a evolução significativa do nível de degradação das estruturas.

Palavras-chave: pontes; Manifestações patológicas; concreto armado; ensaios não destrutivos e semi destrutivos.

\section{ABSTRACT}

Reinforced concrete structures begin to present pathological manifestations when they come close to their useful life or when a problem arises during this period. The purpose of this article is the case study of a building built in 1967 , located on the campus of the Federal University of Pernambuco, which has a report with a survey of the pathological manifestations performed in 2012 and the same year the building received a corrective intervention that was carried out by a company, but there was no structural recovery project. The problems continued and in 2017 a new report was made, which showed the increase in the number of structures that present pathological manifestations. With the conclusion of the work, new construction problems were discovered and it was possible to make an evolution of these problems in 5 years with an increase of almost $300 \%$ in the number of manifestations and the significant evolution of the level of degradation of structures.

Keywords: pathological manifestations; reinforcement corrosion; pathology; reinforced concrete; structural recovery;

\section{INTRODUÇÃO}

A patologia das construções é uma área da engenharia civil que sofreu grande crescimento ao longo dos anos, apesar do termo patologia estar ligado à área de reparo e recuperação de estruturas é comum encontrar casos em que a sua 
aplicação se dá de forma errônea, pois falta a qualificação e conscientização profissional e tem como resultado estruturas que recebem intervenções que não condizem com as normas vigentes.

Inspecionar o processo construtivo sofreu inúmeras mudanças ao longo dos anos. No ano da construção do edifício em estudo (1967), as normas vigentes não contavam com capítulos de proteção a durabilidade da estrutura de concreto armado, como é possível ver hoje na NBR 6118 (ABNT, 2014) ou na NBR 15575 (ABNT, 2013) o que ocasionou grande parte as manifestações patológicas encontradas na estrutura.

Com esse estudo de caso é possível constatar que a ausência de tal conhecimento na época influenciou na situação atual do nível de degradação da estrutura.

\section{PATOLOGIA DAS CONSTRUÇÕES}

O termo Patologia é derivado da palavra grega Phatos (doença) + Logos (estudo, ciência) é utilizado na engenharia civil para o estudo das degradações e manifestações patológicas das estruturas de concreto armado.

Segundo Monteiro (2016), a importância do estudo da patologia é conhecer a evolução dos problemas, estudar as suas causas, fornecer informações para os trabalhos de reparo e manutenção e contribuir para o entendimento do processo de produção minimizando a incidência total de problemas.

O processo de degradação afeta a durabilidade e reduz a vida útil da estrutura, tendo como consequências negativas a falta de estabilidade, de funcionalidade e de estética, causando pânico de usuários em algumas situações. A origem das manifestações patológicas pode ser dividida em 4 itens como:

- Congênitas - Fase de projeto

- Construtivas - Fase de execução

- Adquiridas - Agressividade do meio

- Acidentais - Fenômenos atípicos

\subsection{Vida útil e durabilidade}

A durabilidade está relacionada com as propriedades do material e a sua exposição ao longo do tempo, em função ao ambiente em que a edificação está inserida. Tratar sobre esse assunto é essencial para a compreensão da vida útil das edificações (SOUZA; RIPPER, 1998).

Segundo Monteiro (2016), durabilidade está relacionada ao comportamento físico e funcional de uma determinada construção, individualizando-a pela avaliação da resposta que dará aos efeitos da agressividade ambiental, definindo então, a vida útil da mesma.

Por causa dos efeitos do ambiente, um elemento de construção qualquer, sofre, ao longo do tempo, uma decadência progressiva do seu desempenho, à medida que se alteram os materiais de que é feito. Vida útil de uma estrutura é definida como o período durante o qual a estrutura é capaz de garantir não apenas sua estabilidade, mas todas as funções para qual foi projetada (BERTOLINI, 2010).

Ainda segundo Bertolini (2010), o conceito de durabilidade é um estreitamento associado à definição de vida útil de projeto (ou expectativa): uma estrutura só pode ser considerada durável se sua vida útil for pelo o menos igual à vida útil requerida na fase de projeto.

Na NBR 6118 (ABNT, 2014) diz que, durabilidade consiste na capacidade de a estrutura resistir às influências ambientais previstas e definidas em conjunto pelo autor do projeto estrutural e pelo contratante, no início dos trabalhos de elaboração do projeto.

Segundo Helene (1993), a vida útil global de uma estrutura pode ser subdividida entre: 


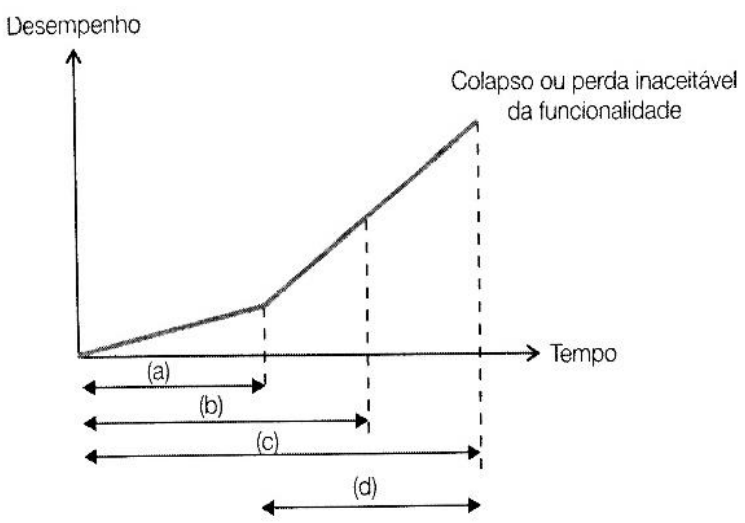

Figura 1: Vida Útil das Estruturas (HELENE, 1993).

(1) Vida útil de projeto (a): Nesta etapa, também conhecida como "período de iniciação", os agentes agressivos, tais como cloretos, $\mathrm{CO}_{2}$, e sulfatos, ainda estão penetrando através da rede de poros de cobrimento, sem causar danos efetivos à estrutura. A vida útil de projeto para estruturas de concreto convencionais é de 50 anos, podendo -se estender para 100 (pontes) ou 200 (barragens).

(2) Vida útil de serviço ou de utilização (b): Os efeitos dos agentes agressivos começam a se manifestar, como fissuração do concreto por ataque químico ou manchas consequentes da corrosão de armaduras. Esta vida útil é difícil de determinar, pois varia em função de cada caso. Ao passo que algumas estruturas não admitem determinadas manifestações, como manchas e eflorescências, outras só serão levadas em consideração quando chegam a níveis que possam comprometer a funcionalidade ou segurança das estruturas.

(3) Vida útil total (c): Corresponde à ruptura e ao colapso parcial ou total da estrutura. Neste momento, a estrutura está condenada ou os custos de reparo são demasiadamente elevados.

(4) Vida útil residual (d): Envolve parte das vidas úteis de serviço e total, correspondendo ao período de tempo no qual a estrutura será capaz de desenvolver as funções, contando após uma vistoria e /ou intervenção.

\subsection{Importância da manutenção preventiva em estruturas de concreto armado}

As edificações são suporte físico para a realização direta ou indireta de todas as atividades produtivas e possuem, portanto, um valor social fundamental. Todavia, as edificações apresentam uma característica que as diferencia de outros produtos: elas são construídas para atender a seus usuários durante muitos anos, e ao longo deste tempo de serviço devem apresentar condições adequadas ao uso a que se destinam, resistindo aos agentes ambientais e de uso que alteram suas propriedades técnicas iniciais, segundo a NBR 5674 (ABNT, 2012).

A (Figura 2) indicada adiante, explica de que maneira a ação da manutenção pode incidir em ganho de vida útil, podendo até prolonga-la ou, ainda, pelo contrário, em caso de negligência por parte do usuário, ensejar a deterioração precoce e a consequente e indesejável desvalorização patrimonial. Segundo Pini (2011), tal condição perfeitamente previsível, portanto, evitável, pode ser minimizada em caso de atuação de manutenção, através da implantação do plano de manutenção das edificações, pelo usuário.

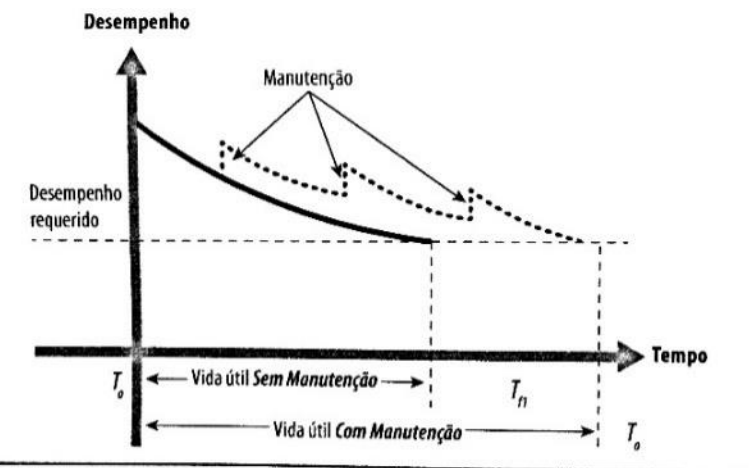

Figura 2: Manutenção X vida útil (PINI, 2011). 


\subsection{Inspeção em estruturas de concreto armado}

A Inspeção Predial deve ser entendida como uma avaliação técnica do "estado de conformidades de uma edificação", como base nos aspectos de desempenho, vida útil, segurança, estado de conservação, manutenção, utilização, operação, observado que sempre o atendimento às expectativas dos usuários (SIQUEIRA, 2012).

É o checkup da edificação, visando à boa qualidade predial e também a boa saúde de seus usuários. Ela requer o diagnóstico de seus sistemas para posteriores de seus sistemas para posteriores providências de reparo e serviços de manutenção predial (GOMIDE, 2014).

\subsubsection{Inspeção preliminar}

Segundo Tutikan e Pacheco (2013), com a inspeção preliminar é possível determinar a natureza e origem do problema, como também de servir como base para um estudo mais detalhado. Para esta etapa recomenda-se utilizar formulários de avaliação.

A ficha de avaliação de antecedentes da estrutura e do ambiente deve buscar informações sobre a estrutura como a idade ou tempo de serviço, natureza e procedência dos materiais constituintes, resistência característica, qualidade e características de construção, idade de início dos problemas, diagnósticos e reparações anteriores, níveis de tensão de trabalho da estrutura, eventuais mudanças de uso, etc. E informações que permitam caracterizar a agressividade do ambiente (TUTIKAN; PACHECO, 2013).

\subsubsection{Inspeção detalhada}

Segundo Helene (1993), a partir da inspeção preliminar, pode ser necessária uma averiguação mais criteriosa da estrutura. Isto vai depender da natureza das anomalias apresentadas e da experiência do analista. É recomendável que sejam abordados nesta investigação mais detalhada o que segue:

- Fichas, croquis e planos de levantamento de danos;

- Plano de amostras;

- Tabela de tipificação de danos;

- Técnicas de ensaio/medição/analises adequadas;

- Regiões onde deverão ser realizados os ensaios;

- Planificação de materiais e equipamentos;

No final de uma inspeção detalhada devem ser disponibilizados todos os dados necessários à caracterização dos danos existentes, de forma a realizar um diagnóstico sobre o estado da estrutura, bem como prever o seu comportamento no futuro (MONTEIRO, 2016).

\subsection{Manifestações patológicas}

Segundo Souza e Ripper (1998), ao se analisar uma estrutura de concreto "doente" é absolutamente necessário entender-se o porquê do surgimento e do desenvolvimento da doença, buscando esclarecer as causas, antes da prescrição e consequente aplicação do remédio necessário. O conhecimento, das origens da deterioração é indispensável, mas para garantir que, após reparada, a estrutura não volte a se deteriorar.

Devido as suas interações com o meio ambiente no qual estão expostas, as estruturas de concreto sofrem alterações que podem, com o passar do tempo, comprometer a sua estabilidade funcionalidade (RIBEIRO et al., 2014).

Quando uma edificação fica "doente", ou apresenta algum problema em sua integridade, podem surgir sinais externos, sintomas, indicando que algo não está correto. Algumas vezes esses sinais externos demoram para aparecer e outras podem ser imperceptíveis à maioria dos leigos. A sintomatologia se preocupa em estudar esses sinais com o objetivo de diagnosticar aquela manifestação ou problema patológico (LIMA, 2015). 


\subsubsection{Bolor}

Segundo Lima (2015), bolor ou mofo é constituído pela colonização de diversas populações de fungos filamentosos que sobrevivem da desmaterialização dos componentes das estruturas de concreto.

Para se proliferarem precisam de uma adequada condição que pode ser dada através de infiltrações, umidade da obra, condensação do vapor da água, umidade proveniente do solo e umidade proveniente de vazamentos. Ambientes com pouca ventilação e baixa incidência de luz são propícios a esse tipo de manifestação patológica (LIMA, 2015). Na (Figura 3) é possível observar manchas de umidade e bolor em pilar de fachada.

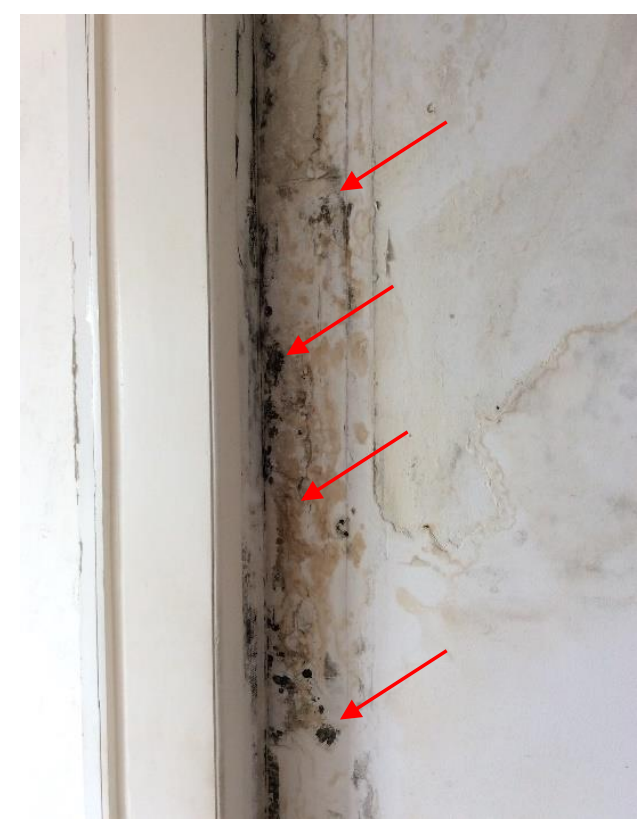

Figura 3: Bolor e manchas de umidade (LIMA, 2015).

\subsubsection{Corrosão das armaduras}

Corrosão pode ser entendida como a interação destrutiva de um material com o meio ambiente, como resultado de reações deletérias de natureza química ou eletroquímica, associadas ou não a ações físicas ou mecânicas de deterioração (RIBEIRO et al., 2014).

O concreto oferece ao aço uma dupla proteção, primeiro uma proteção física, separando o aço do contato direto com o meio externo e, segundo uma proteção química, conferida pelo $\mathrm{pH}$ do concreto, o qual promove a formação de uma película passivadora que envolve o aço (PAZINI; MEIRA, 2013).

Segundo Lima (2015), o mecanismo de corrosão das armaduras estudado é o por corrosão eletroquímica ou eletrolítica. Encontra-se pela geração de um potencial elétrico na presença de um eletrólito (concreto) em contato com um condutor metálico (barra de aço).

Podendo ser localizada, caracterizada pela ação de íons agressivos (cloretos), sempre que haja umidade e presença de oxigênio, ou generalizada, função da redução do pH do concreto pela ação dissolvente do gás carbônico existente no ar atmosférico.

No caso de armaduras de concreto, os efeitos degenerativos manifestam-se na forma de manchas superficiais causadas pelos produtos de corrosão, seguidas por fissuras, destacamento do cobrimento do concreto (como é possível observar na (Figura 4), redução da secção da armadura, perda da aderência entre o concreto e a armadura e eventualmente o colapso (MONTEIRO (2016). 


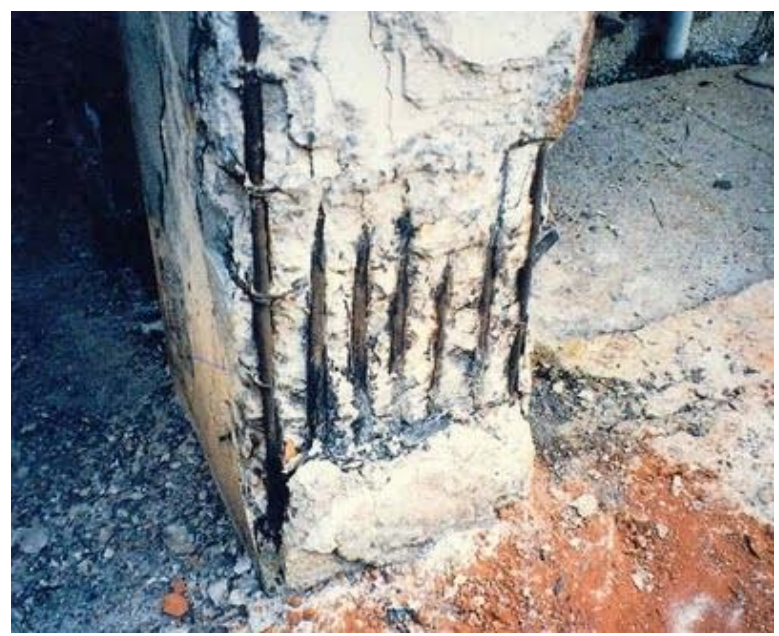

Figura 4: Corrosão de armaduras em um pilar (HELENE, 1993).

\subsubsection{Trincas e fissuras}

Dentre os inúmeros problemas patológicos que afetam os edifícios, particularmente importante é o problema das trincas, devido a três aspectos fundamentais: o aviso de um eventual estado perigoso para a estrutura, o comprometimento do desempenho da obra em serviço e o constrangimento psicológico que a fissuração do edifício exerce sobre seus usuários (THOMAZ, 1989).

São inúmeros os fatores que acarretam a fissuração nas estruturas, mas a que veremos nesse estudo de caso é a fissuração por corrosão de armaduras. Segundo Thomaz (1989), por serem peças colocadas próximo a superfície das estruturas de concreto, no caso de cobrimento insuficientes ou de concreto mal adensado, as armaduras ficarão sujeitas à presença de água e de ar, podendo-se desencadear então um processo de corrosão.

Independentes de sua natureza, as reações de concreto, produzem óxido de ferro, cujo volume é muitas vezes maior do que o original do metal. Essa expansão provoca o fissuramento e o lançamento do concreto nas regiões próximas às armaduras, conforme é possível observar na (Figura 5).

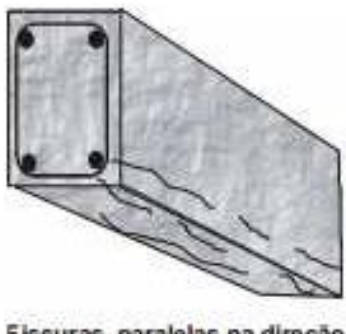

Fissuras paralelas na direçāo das barras principais

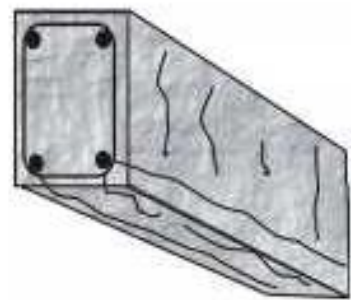

Fissuras paralelas as barras principais e estribos

$2 \% \leq \triangle \leq 5 \%$

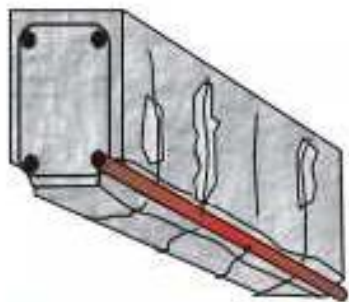

Resplacamento da cobertura de concreto e armadura exposta

$$
\triangle \geq \mathbf{5} \%
$$

Figura 5: Fissuras por corrosão de armaduras (HUSNI et al., (2003)).

\section{ESTUDO DE CASO}

\subsection{Descrição da edificação}

O edifício foi construído em 1967 e abriga pessoas em situação de vulnerabilidade socioeconômica e fica lozalizado em Recife/PE. A edificação é dividida em térreo, onde fica a área comum, com biblioteca, copa, sala de informática, sala de 
segurança, recepção, entre outros, três pavimentos tipo, cada pavimento possui 16 quartos, e cada quarto tem capacidade para 4 pessoas, 1 copa e 4 banheiros e coberta como mostrado na (Figura 6). A fundação da edificação foi executada em sapata isolada e a superestrutura em concreto armado com 56 pilares, 28 vigas, lajes maciças e treliçadas.

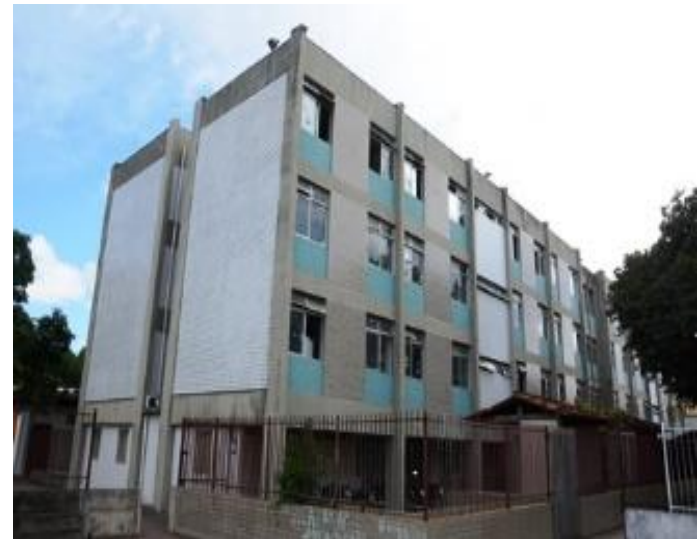

Figura 6: Edifício com finalidade coletiva (público).

O edifício se encontra em situação de vulnerabilidade devido a sua localização que está aproximadamente $3 \mathrm{~km}$ de distância do limite da costa em linha reta, porém Recife é uma cidade que está situada em uma região considerada como zona de agressividade forte e muito forte de acordo com a NBR 6118 (ABNT, 2014). Além disso, a presença de íons cloretos e gás carbônico na atmosfera é bem presente, onde as incidências patológicas das edificações dar-se-á devido a maresia, a poluição ambiental e fatores funcionais.

\subsection{O laudo do ano de 2012}

Foi executado em 20 de novembro de 2012, pela Universidade Federal de Pernambuco, com o título de: Laudo de vistoria e parecer na obra de reforma da edificação pública - $3^{\circ}$ etapa, referente às manifestações patológicas encontradas na estrutura de concreto. O conteúdo que serviu como análise comparativa dos problemas observados não possui autores identificados.

Acompanhado com o laudo, foi disponibilizado um projeto identificando onde se encontravam manifestações patológicas apontados nas regiões com setas vermelhas, como é possível ver na (Figura 7).

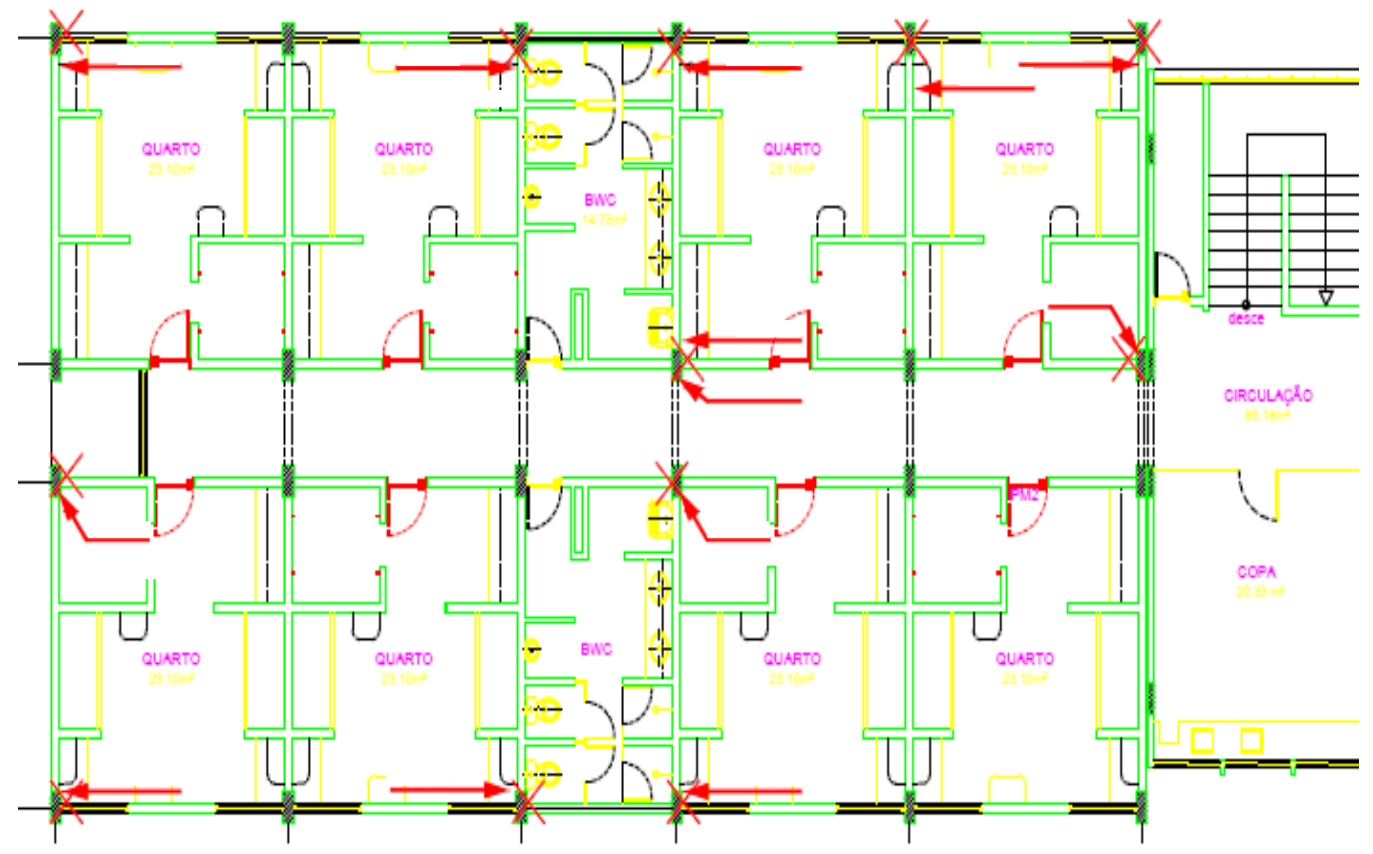

Figura 7: Planta do $3^{\circ}$ pvto com indicações das manifestações patológicas (UFPE, 2012). 
Segundo o laudo, foi observado um padrão nas manifestações patológicas encontradas, em sua maioria os problemas ocorreram nos quartos anexos aos banheiros, nos quais apresentavam vazamentos e ausência de cobrimento.

No relatório fotográfico do Laudo de 2012, foi possível observar que a estrutura apresentava corrosão de armadura aparente, principalmente nas estruturas próximas aos banheiros como pode-se ver na (Figura 8), que apresenta corrosão em viga e pilar próximos ao banheiro do $2^{\circ}$ pavimento. E na (Figura 9), observa-se uma laje de banheiro que apresenta manchas de corrosão e corrosão aparente.

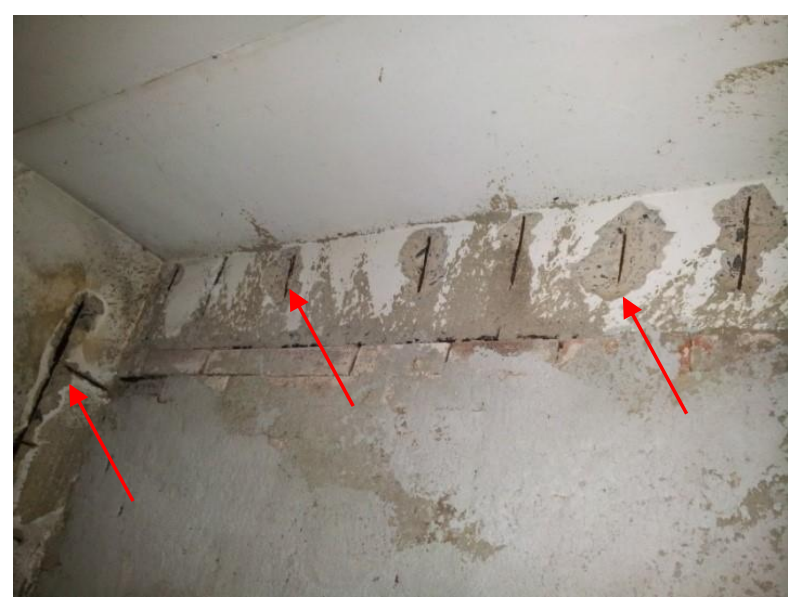

Figura 8: Pilar e viga com corrosão aparente (UFPE, 2012).

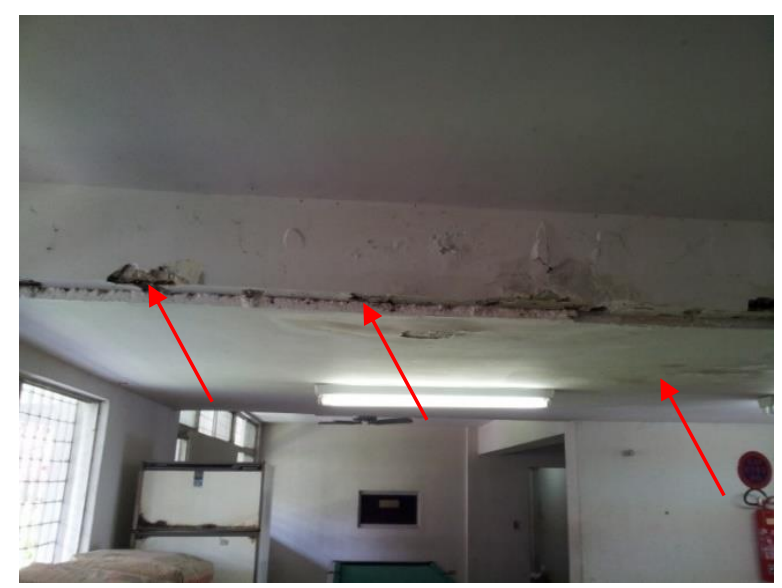

Figura 9: Manchas de corrosão, fissuras e corrosão aparente (UFPE, 2012).

\subsection{O laudo do ano de 2017}

Após 5 anos da elaboração do $1^{\circ}$ Laudo, foi realizado um novo laudo técnico para acompanhamento do crescimento das manifestações patológicas e também para investigar novos problemas encontrados. Durante a vistoria de levantamento das manifestações patológicas, foi identificado que alguns pilares na edificação sofreram uma recuperação estrutural feita por uma empresa, mas não constava projeto de recuperação e nem os dados de quando foi executado.

A estrutura de concreto armado dos banheiros, foi construída com uma laje rebaixada para "esconder" as tubulações hidráulicas, o que hoje em dia é feito com forro. Essa laje rebaixada, foi preenchida com areia antes da execução do contrapiso.

Devido a infiltrações e vazamentos, a areia da laje rebaixada (Figura 10), encontrava-se sempre úmida, ocasionando em um ambiente perfeito com umidade que favorece a cinética da corrosão de armaduras. Com isso, foi possível identificar no laudo executado em 2017, que todas as vigas dos banheiros do $1^{\circ}$ ao $3^{\circ}$ pavimento apresentavam corrosão de armaduras aparente. 

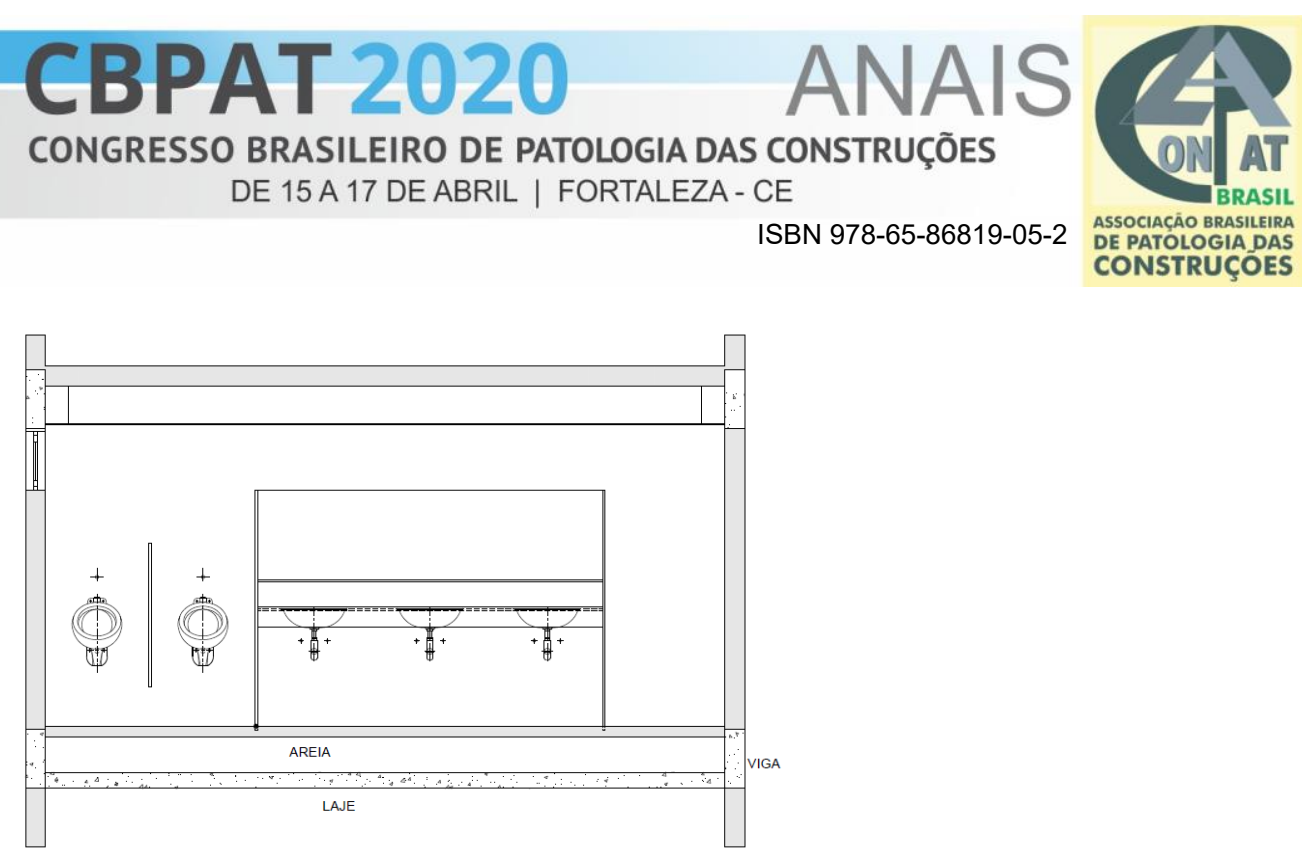

Figura 10: Corte banheiro pavimento tipo.

Na vistoria foi possível diagnosticar uma série de vigas quebradas para passagem de tubulações hidráulicas, como podese observar na (Figura 11) e um crescimento elevado do quantitativo de peças que apresentavam algum tipo de manifestação patológica.

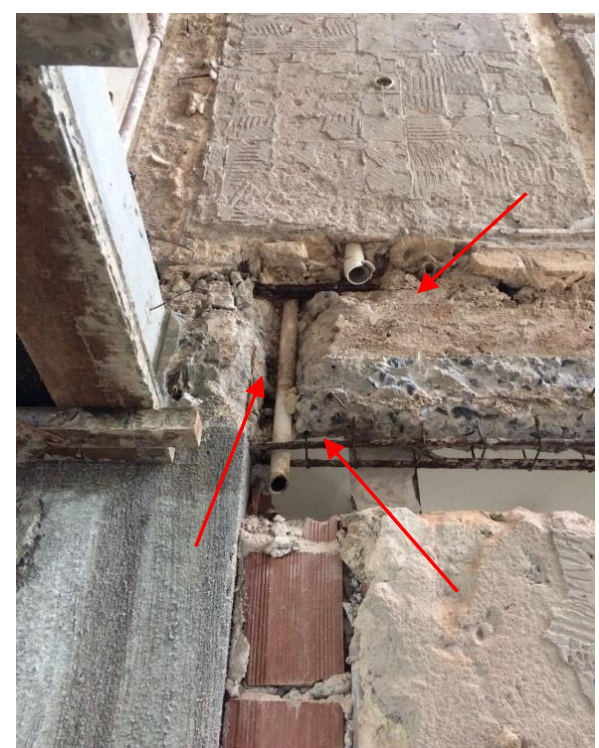

Figura 11: Viga seccionada em encontro com pilar para passagem de tubulação hidráulica.

$\mathrm{Na}$ (Figura 12) é possível observar a parede da caixa d'água superior repleta de bolor e na (Figura 13) corrosão aparente em pilar de fachada no $3^{\circ}$ pavimento.

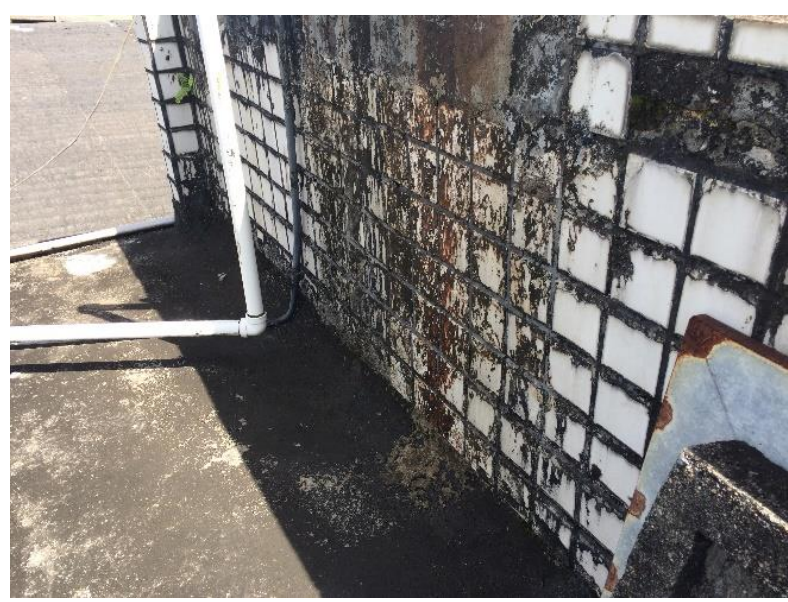

Figura 12: Bolor em parede da caixa d'água. 


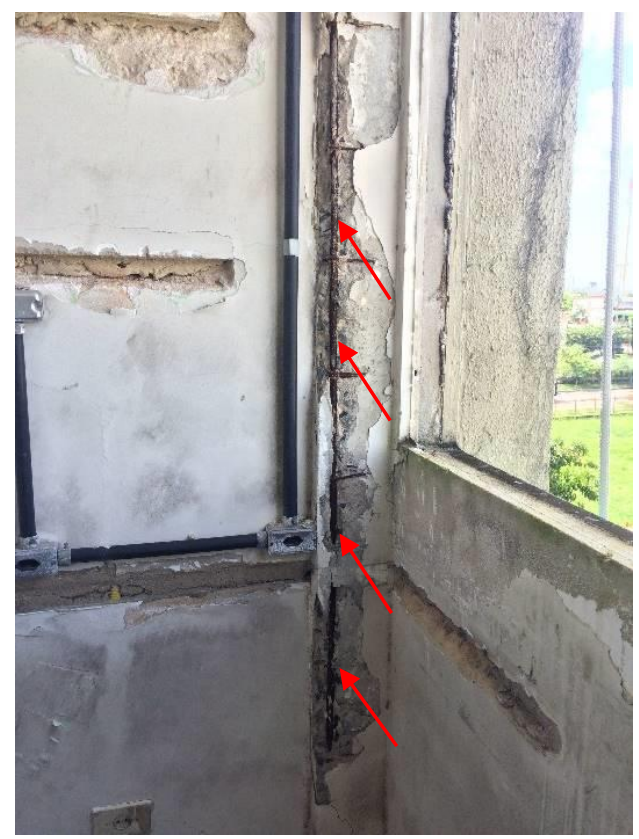

Figura 13: Corrosão aparente em pilar da fachada.

\subsection{Comparativo dos Laudos dos anos de 2012 e 2017}

\subsubsection{Aumento do quantitativo de manifestações patológicas}

A quantificação das manifestações patológicas foram realizadas in loco, levando em consideração o nível de deterioração dos elementos estruturais de concreto por inspeção visua, de forma conjunta.

Essa quantificação serviu apenas para efeito de vulnerabilidade estrutural, visto que, a falta de manuteção preventiva e/ou corretiva pode acarretar no aumento dessas incidências.

No intervalo de tempo de 5 anos entre os laudos, pode-se observar um aumento significativo na quantidade de estruturas que apresentaram manifestações patológicas, visto através do (Quadro 1) e da (Figura 14).

Quadro 1 - Aumento das manifestações patológicas $2012-2017$.

\begin{tabular}{|c|c|c|}
\cline { 2 - 3 } \multicolumn{1}{c|}{} & 2012 & 2017 \\
\hline TÉRREO & 5 & 5 \\
\hline $1^{\circ}$ ANDAR & 9 & 35 \\
\hline $2^{\circ}$ ANDAR & 13 & 38 \\
\hline $3^{\circ}$ ANDAR & 18 & 50 \\
\hline
\end{tabular}

\begin{tabular}{|l|l|l|} 
TOTAL & 45 & 128 \\
\hline
\end{tabular}

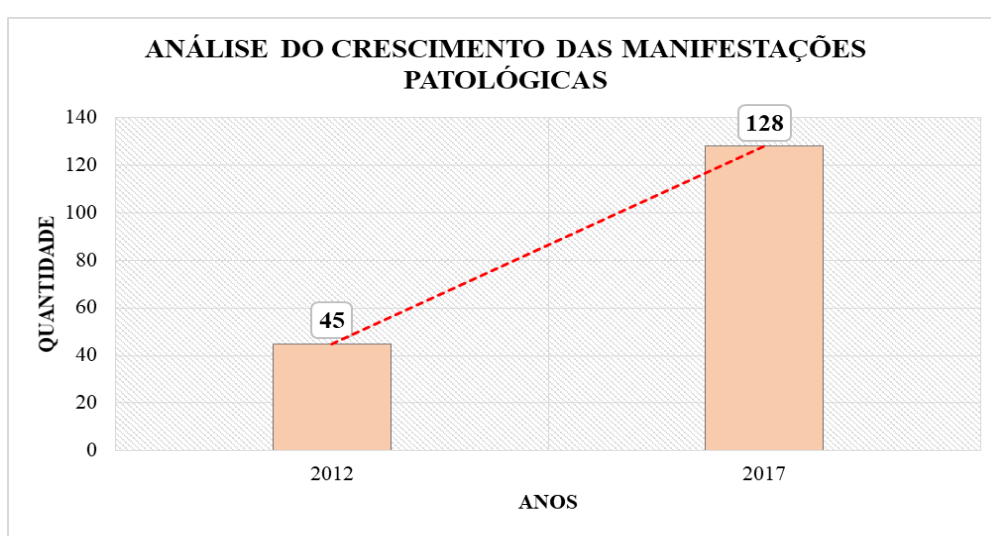

Figura 14: Análise da evolução das manifestações patológicas.

A maior incidência de novos pontos de manifestações patológicas se deu no $3^{\circ}$ pavimento, pois o edifício apresenta infiltrações na coberta e na caixa d'água, o que torna o ambiente adequado para a proliferação das manifestações patológicas influenciadas pela presença de umidade. 


\section{CBPAT 2020 \\ concerss a ass \\ DE 15 A 17 DE ABRIL | FORTALEZA - CE}

\subsubsection{Aumento do nível de deterioração das manifestações patológicas}

O nível de deterioração encontrado nas estruturas de concreto do edifício em questão agravou em relação ao laudo de 2012. Os sintomas de corrosão de armadura obedecem um ciclo: Manchas Superficiais; Fissuração; Redução da secção da armadura; Expansão; Destacamento do cobrimento; Perda da aderência da armadura; Colapso (LIMA et al., 2019; SILVA; MONTEIRO; VITÓRIO, 2017; NASCIMENTO et al., 2019).

No intervalo de 5 anos e observando as regiões deterioradas da viga de fundo da laje (Figura 15) houve um agravamento no nível de deterioração da estrutura, que em 2012 apresentava manchas de umidade e corrosão e em 2017 já era possível observar que a viga já sofria com desplacamento da camada superficial do concreto.

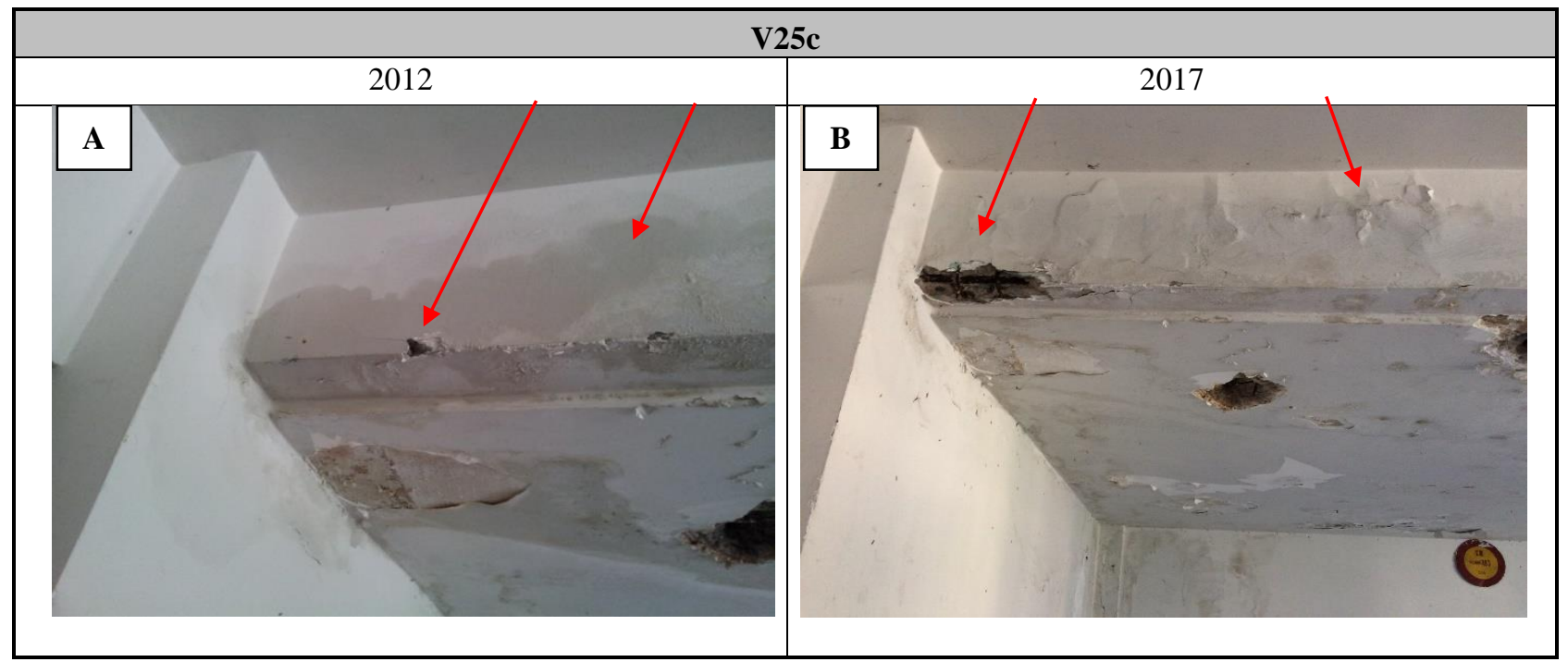

Figura 15: Unidade, infiltração e corrosão (A); Desplacamento superficial do concreto (B).

Na (Figura 16) o objeto de estudo foi a estrutura de um pilar de fachada do $3^{\circ}$ pavimento, que em 2012 apresentava apenas fissuras longitudinais condizentes com a tipologia de fissuras de corrosão de armaduras e em 2017 o mesmo pilar apresentava corrosão aparente, desplacamento de concreto e estribos rompidos.

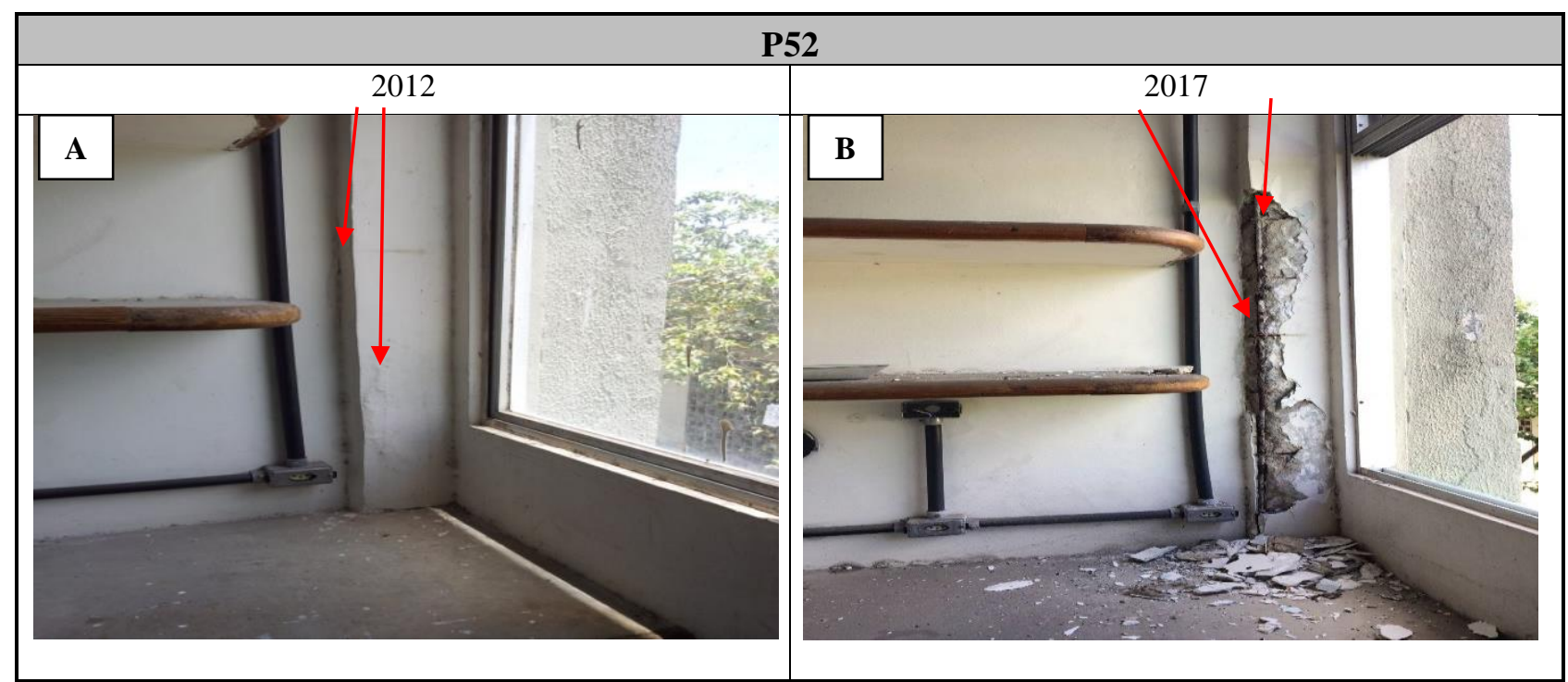

Figura 16: Fissuras paralela as armaduras (A); Corrosão aparente em pilar de fachada (B).

O pilar P39 apresentou grande evolução no nível de degradação, no $2^{\circ}$ pavimento é possível ver essa evolução na (Figura 17) na foto tirada em 2012, onde o pilar apresentava apenas algumas fissuras longitudinais e na foto tirada em 2017, onde o pilar apresentava corrosão aparente e desplacamento de concreto. 


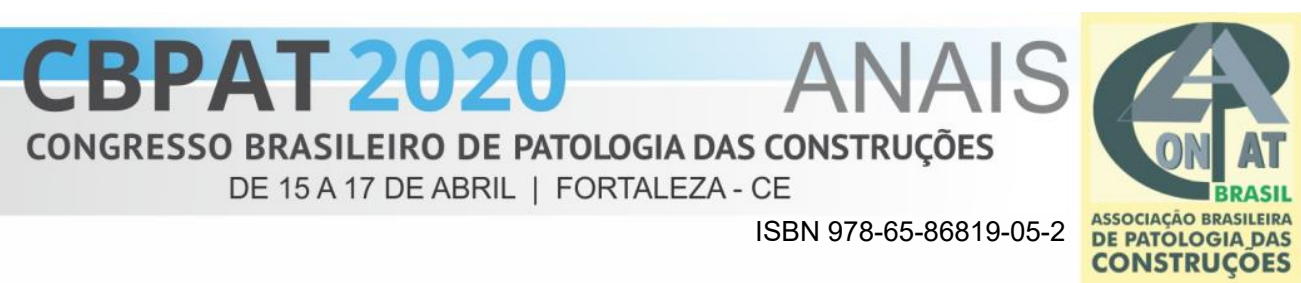

O mesmo pilar, P39, apresentou uma evolução ainda mais agressiva no $3^{\circ}$ pavimento, como pode-se ver na (Figura 18), pois em 2012, ele já apresentava corrosão aparente e desplacamento de concreto e em 2017 a armadura estava praticamente toda exposta, com perda de secção e estribos rompidos, além de desplacamento de concreto.

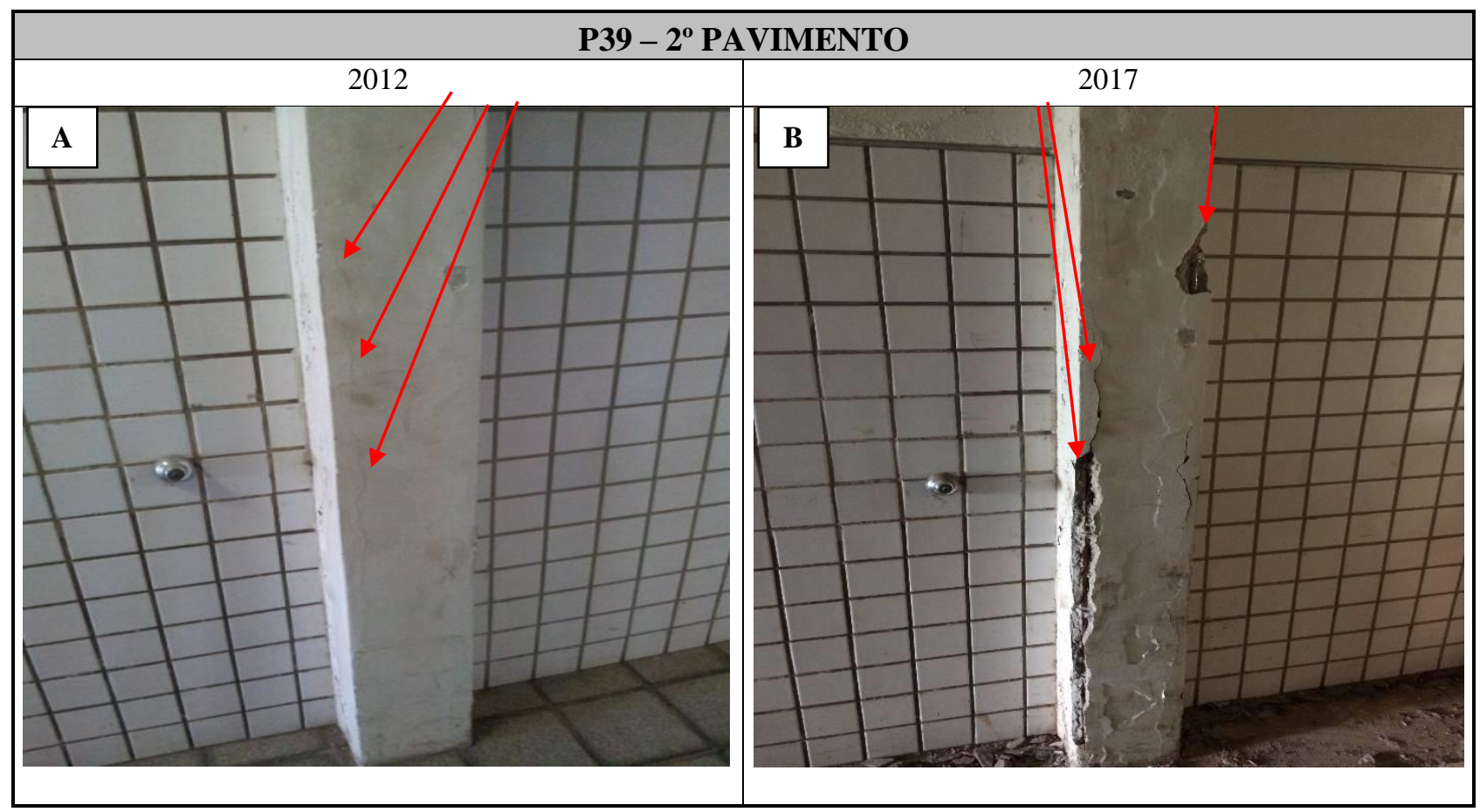

Figura 17: Fissuras longitudinais no pilar do sanitário (A); Corrosão generalizada e desplacamento do concreto (B).

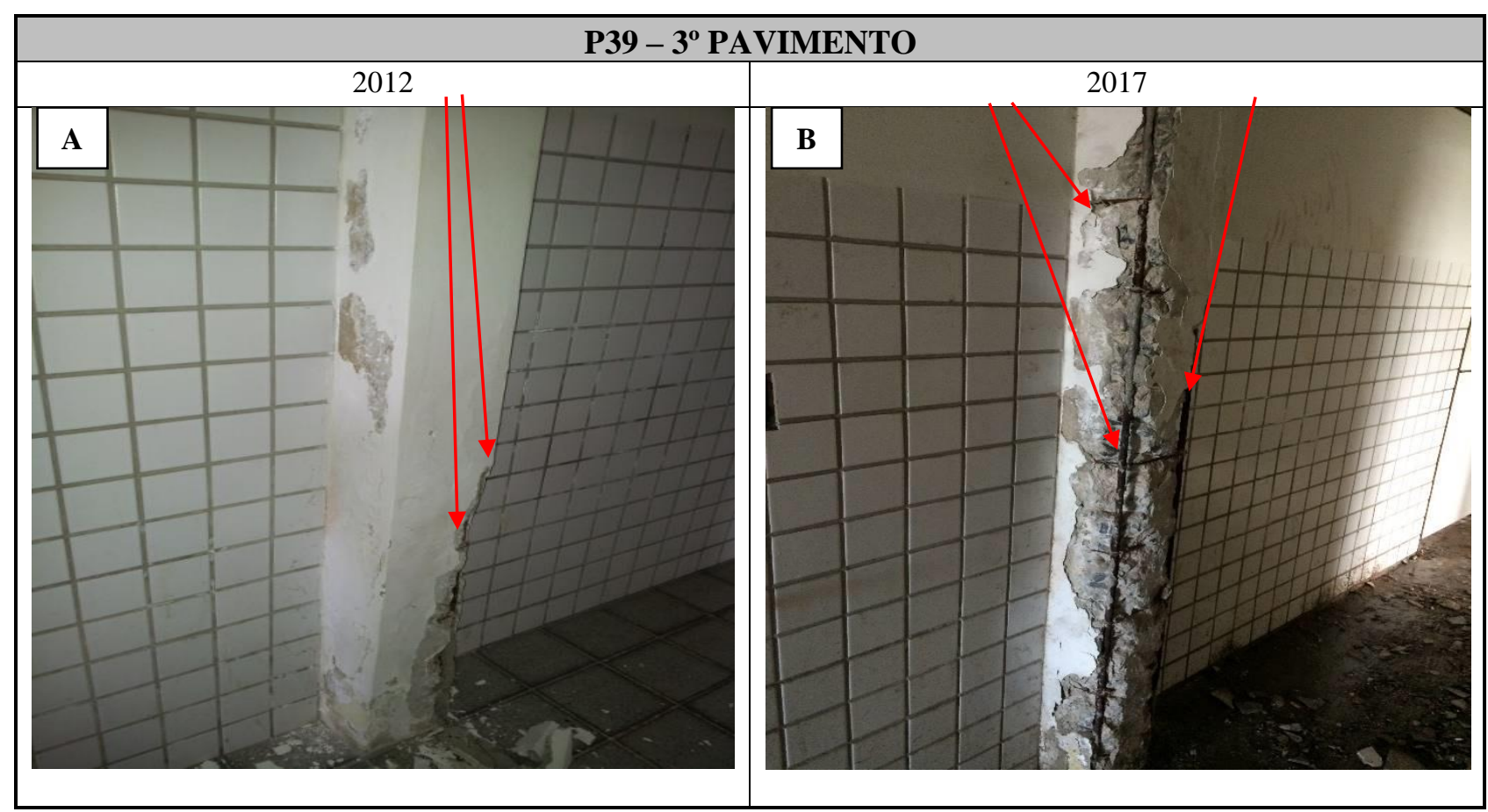

Figura 18: Desplacamento do concreto (A); Armadura completamente exposta e perda de seção das mesmas (B). 


\section{CONCLUSÕES}

Tendo em vista que as estruturas de concreto armado estão sujeitas ao aparecimento de diversas manifestações patológicas ao longo da sua vida útil, se faz necessário o acompanhamento e a execução das devidas manutenções como é descrito no Manual de Uso e Operação segundo a NBR 5674 (ABNT, 2012).

Quando os agentes agressivos começam a se manifestar, como fissuração do concreto por ataque químico ou manchas consequentes da corrosão de armaduras é sinal de que se faz necessário uma intervenção corretiva. Com o estudo de caso é possível constatar a evolução do nível de degradação das estruturas e o crescimento da quantidade de estruturas que apresentaram alguma manifestação patológica ao longo de um intervalo de 5 anos.

Essa análise do crescimento serve como alerta para que seja respeitado as manutenções previstas na estrutura e que as manifestações patológicas continuam a se agravar ao longo do tempo até a estrutura entrar em colapso. Após o comparativo entre os laudos dos anos de 2012 e 2017 foi possível constatar que houve um aumento de quase 300\% no quantitativo de estruturas que apresentaram manifestações patológicas. Houve também um aumento do nível de deterioração das manifestações patológicas reincidentes.

\section{REFERÊNCIAS}

ABNT - ASSOCIAÇÃO BRASILEIRA de NORMAS TÉCNICAS. Manutenção de edificações - Requisitos para o sistema de gestão de manutenção. NBR 5674. Rio de Janeiro, 2013.

ABNT - ASSOCIAÇÃO BRASILEIRA DE NORMAS TÉCNICAS. Edificações habitacionais - Desempenho. Procedimento. NBR 6118. Rio de Janeiro, 2014.

ABNT - ASSOCIAÇÃO BRASILEIRA DE NORMAS TÉCNICAS. Projeto de Estruturas de concreto. Procedimento. NBR 6118. Rio de Janeiro, 2014.

BERTOLINI, L. Materiais de construção: patologia, reabilitação e prevenção. Oficina de Textos, 2010.

GOMIDE T. L. F. et al. Inspeção predial total: diretrizes e laudos no enfoque da qualidade total e engenharia diagnóstica. São Paulo, PINI, 2014.

HELENE, P. Contribuição ao estudo da corrosão em armaduras de concreto armado. São Paulo: USP, 1993. Tese (livre docência). Escola Politécn9ca da Universidade de São Paulo, 1993.

HELENE, P. Vida Útil das Estruturas de Concreto. In: Congresso Ibero Americano de Patologia das Construções, 4, Congresso de Controle da Qualidade, 6, , 1997, Porto Alegre. Proceedings... Porto Alegre: CONPAT-97, 1997. v. 1, p. 1-30.

HUSNI, R.; BENÍTEZ, A.; MANZELli, A.; MACCHI, C.; CHARREAU, G.; RISETTO, J.; LUCO, L. F.; GUITTELMAN, N.; MORRIS, W. Ações sobre as estruturas de concreto. In: HELENE, P. Manual de reparo, proteção e reforço de estruturas de concreto. Red Rehabilitar, 2005. 1, p.37-104.

LIMA, H. J. N.; RIBEIRO, R. S.; PALHARES, R. A.; MELO, G. S. S. A. Análise de manifestações patológicas do concreto em viadutos urbanos. Revista Alconpat, [s.1.], v. 9, n. 2, p.247-259, 30 abr. 2019. Revista ALCONPAT. http://dx.doi.org/10.21041/ra.v9i2.308.

LIMA, N. M. L. Estudo de caso de uma edificação residencial em cidade litorânea - levantamento das manifestações patológicas. 2015. 1 v. TCC (Graduação) - Curso de Engenharia Civil, Centro de Ciências e Tecnologia, Universidade Católica de Pernambuco, Recife, 2015.

MONTEIRO, E. Notas de aula: Pós-Graduação de Inspeção, Manutenção e Recuperação de Estruturas - UPE, 2016.

NASCIMENTO, C. F. G.; SOUZA, P. M. C. O.; SILVA, T. M.; SANTOS, M. S. C.; VALÕES, D. C. P.; FIGUEIRA, A. M. A.; CAVALCANTI, L. R.; PASSOS NETO, G. M.; MONTEIRO, E. C. B. Utilização do método dos fatores para 
priorização de incidências patológicas na ponte Barão de Jundiá, 48 anos de construção no município de EscadaPE. Revista Científica Semana Acadêmica, ceará, v. 01, n. 176, p.1-17, ago. 2019.

PAZINI, E.; MEIRA, G. Corrosão das armaduras das estruturas de concreto. Boletim técnico ALCONPAT, 2013.

PINI, M. S. Manutenção Predial - São Paulo: PINI, 2011.

RIBEIRO, D. V. et al. Corrosão em estruturas de concreto armado: teoria, controle e métodos de análise. Organização Daniel Ribeiro. ELSEVIER, Rio de Janeiro. 2014

SILVA, C. J. G.; MONTEIO, E. C. B.; VITÓRIO, J. P. A. Condições estruturais e funcionais de pontes e viadutos das rodovias federais de Pernambuco. Revista Alconpat, [s.1.], v. 8, n. 1, p.79-93, 31 jan. 2018. Revista ALCONPAT. http://dx.doi.org/10.21041/ra.v8i1.199.

SIQUEIRA, A. P. Inspeção predial: check-up predial: guia da boa manutenção/ IBAPE-SP- Instituto Brasileiro de Avaliações e Perícias de Engenharia em São Paulo- Liv. E Ed. Universitária de Direito, 2012.

SOUZA, C. M.; RIPPER, V. Patologia, recuperação e reforço de estruturas de concreto. Editora PINI, 1998.

THOMAZ, E. Trincas em edifícios - causas, prevenção e recuperação. São Paulo: PINI, 1989.

TUTIKAN, B.; PACHECO, M. Inspeção, diagnóstico e prognóstico na construção civil. Boletim técnico ALCONPAT, 2013.

UFPE - UNIVERSIDADE FEDERAL DE PERNAMBUCO. Laudo de vistoria e parecer na obra de reforma da edificação pública $-3^{\circ}$ etapa. Recife, 2012. 